\title{
La educación desde la perspectiva de Tomás de Aquino en el contexto de la cibercultura
}

\author{
FRAY RODRIGO GARCÍA JARA, O. P.*
}

ÉDGAR PINEDA**

Artículo de reflexión sobre hallazgos de la fase de estado del arte del proyecto de investigación "Cibercultura y educación en perspectiva de Tomás de Aquino”, que busca develar los aportes de Tomás de Aquino a los preceptos de la educación digital.

Recibido: 20 de febrero de 2020 - Evaluado: 24 de junio de 2020 - Aceptado: 29 de junio de 2020

Citar como: García, R. y Pineda, É. (2021). La educación desde la perspectiva de Tomás de Aquino en el contexto de la cibercultura. Hallazgos, 18(35), 319-339. https://doi.org/10.15332/2422409X.5497

* Doctorando en Educación. Vicerrector Académico de la Universidad Santo Tomás, Sede Villavicencio, Colombia.

Correo electrónico: frayrodrigogarcia@usantotomas.edu.co

ORCID: https://orcid.org/0000-0001-7096-7119

** Doctor en Ciencias Sociales (humanidades y sociedad digital) y doctor en Educación. Docente de la Unidad de Humanidades de la Universidad Santo Tomás, Sede Villavicencio, Colombia.

Correo electrónico: edgarpineda@usantotomas.edu.co

orCID: https://orcid.org/0000-0001-6738-0237 


\section{Resumen}

En este artículo se ofrece una reflexión sobre la educación en el siglo xxI, desde la perspectiva de Tomás de Aquino. De esta manera, propicia una actualización de las cuestiones decisivas de la práctica pedagógica desde una perspectiva realista, humana y ética, basada en el ideario educativo y pedagógico de Tomás de Aquino, en el contexto de la cibercultura. Para esto, se exponen las implicaciones antropológicas, epistemológicas y axiológicas del pensamiento de Tomás de Aquino, con el fin de aplicarlas a la práctica educativa con base en el realismo pedagógico. Con esta finalidad, se optó por realizar un diseño cualitativo de corte hermenéutico, en el que se triangulan los textos de Santo Tomás frente a los textos clásicos de la cibercultura y la convergencia cibercultural. Con base en esto, se proponen algunas líneas de acción para estimular la reflexión del diseño curricular, según los conceptos de persona, verdad y virtud, propios de Santo Tomás, ampliamente emergentes en la llamada sociedad digital.

Palabras clave: Educación; Realismo pedagógico; Tomás de Aquino; Virtudes. 


\title{
Education from Thomas Aquinas' perspective in the context of cyberculture
}

\begin{abstract}
This article offers a reflection on education in the $21^{\text {st }}$ century, from the perspective of Thomas Aquinas. Thus, it promotes an updating of the decisive issues of pedagogical practice from a realistic, human and ethical perspective, based on Thomas Aquinas' educational and pedagogical ideology, in the context of cyberculture. To this end, the anthropological, epistemological and axiological implications of Thomas Aquinas' thought are presented, with the purpose of applying them to educational practice based on pedagogical realism. With this objective, we have chosen to make a qualitative design of hermeneutic nature, in which the texts of Saint Thomas are triangulated with the classic texts of cyberculture and cybercultural convergence. Based on this, some lines of action are proposed to stimulate the reflection of the curricular design, according to the concepts of person, truth and virtue, distinctive of Saint Thomas, widely emerging in the so-called digital society.
\end{abstract}

Keywords: Education; Pedagogical realism; Thomas Aquinas; Virtues.

\section{A educação sob a perspectiva de Tomás de Aquino no contexto da cibercultura}

\section{Resumo}

Neste artigo, é apresentada uma reflexão sobre a educação no século XXI, sob a perspectiva de Tomás de Aquino. Dessa maneira, propicia uma atualização das questões decisivas da prática pedagógica sob uma perspectiva realista, humana e ética, baseada no ideário educativo e pedagógico de Tomás de Aquino, no contexto da cibercultura. Para isso, são expostas as implicações antropológicas, epistemológicas e axiológicas do pensamento dele, a fim de aplicá-las à prática educacional com base no realismo pedagógico. Com esse objetivo, optou-se por realizar um desenho qualitativo de corte hermenêutico, no qual são triangulados os textos de São Tomás ante os textos clássicos da cibercultura e da convergência cibercultural. Com base nisso, são propostas algumas linhas de ação para estimular a reflexão do desenho curricular, segundo os conceitos de pessoa, verdade e virtude, próprios de São Tomás, amplamente emergentes na chamada "sociedade digital".

Palavras-chave: Educação; Realismo pedagógico; Tomás de Aquino; Virtudes. 


\section{Introducción}

Tomás de Aquino no elaboró un tratado sistemático sobre la educación; sin embargo, el carácter pedagógico de sus textos reafirma el papel activo que la persona posee en el proceso de aprendizaje. Según el santo, lo esencial radica en la formación integral, la formación de la libertad y las virtudes como fundamentos de cualquier proyecto educativo. En este orden de ideas, según Martínez (2003):

Para Santo Tomás, educar es, en cierta medida, ayudar a ser [...]. En Santo Tomás encontramos una pedagogía perenne al estar fundamentada sobre roca, esto es sobre saber acerca del hombre, de su fin, de sus necesidades. Y si es perenne, también puede iluminar hoy el quehacer educativo. (pp. 5,11)

Así, educar es enseñar para el ser, el conocimiento y la búsqueda de la verdad y el bien; la educación es virtuosa (verdad y bien) y emancipadora por cuanto permite interactuar con el otro, haciendo debate de las diferencias con el fin de descubrir la verdad. Tomás de Aquino señala que el respeto a la dignidad de la persona es el rasgo esencial del acto educativo, por tal razón, resulta pertinente discutir sobre qué significa educar en la actual sociedad digital o cibercultura (Lévy, 2007). Nuevamente, las intenciones morales, las mentalidades políticas y los horizontes culturales se convierten en preocupaciones del quehacer educativo; sus actores y temporalidades han comprendido que estamos en un mundo que rebasa los límites de lo físico y lo material, y que la persona, desde su dignidad, su virtud y su bondad, es necesidad latente para convivir y pervivir en una sociedad con tendencias de consumo y con preocupaciones más cercanas al inmediatismo que a la trascendencia.

En este sentido, la cibercultura, con sus vertiginosos cambios a nivel social, económico, ambiental y cultural, exige asumir nuevos retos por parte de la educación, en aras de generar mayor preparación y responsabilidad. Esta situación produce interrogantes en los educadores, tales como: ¿cuál es el papel de la educación en la sociedad contemporánea?, ¿este papel consiste en preparar para una sociedad digital?, ¿qué se educa, qué es educable y qué es educación en la cibercultura?, ¿cuál es el papel de la moral y las emociones en la educación actual?, ¿qué es la formación integral? Para resolver estos interrogantes, es necesario comprender la tesis de Aquino según la cual la persona es el centro de la acción educativa y un ser concreto, educable, que busca la verdad y el amor. Teniendo en cuenta todo esto, es momento de pensar o repensar el papel de la educación en el proceso de autorrealización y plenitud en el contexto de la cibercultura. 
El diseño metodológico que adoptó esta investigación tiene que ver con el análisis y cruce de fuentes primarias en los temas de cibercultura, contrastados con textos propios de Tomás de Aquino. En este orden de ideas, se trabajaron los siguientes textos de este autor: Suma Contra Gentiles (1259-1265), Suma Teológica [sT] (1268-1272), Comentario a la Política de Aristóteles (1269-1272) y los Comentarios a la Ética de Aristóteles (1271-1272); en cuanto al núcleo temático de la cibercultura, se trabajaron principalmente textos de Lévy (2007), Aparici y García (2018) y Jenkins (2008).

\section{Descubrir y conocer, conceptos clave para entender lo educativo desde Tomás de Aquino}

Antes de iniciar una discusión epistemológica sobre la pregunta: ¿qué es conocer para Santo Tomás de Aquino?, es importante retomar esta otra: ¿quién es una persona para el santo?, puesto que la clave para entender esta episteme tomista es abordarla desde una perspectiva antropológica. Así, para Tomás de Aquino la naturaleza de ser persona tiende al bien, ya que esta proviene de Dios mismo y, de esta manera, su naturaleza es de conservación y cuidado, de prudencia y de búsqueda. Por tal razón, la persona es "sustancia individual de naturaleza racional” (Tomás de Aquino, 1998, ST Prima pars, qu.34, ar.3, ra.1).

Pero, ¿qué es entonces sustancia individual y naturaleza racional? La primera indica que el ser humano, en cuanto sujeto completo y acabado, posee integridad en su ser individual y único. La naturaleza racional, por su parte, es la relación que existe entre el intelecto y la voluntad, que los convierte en una sola entidad (Martínez, 2003).

De esta manera podemos comprender que, para Santo Tomás, la persona es un individuo racional que se caracteriza por su singularidad, pero también un sujeto que comprende y discierne las diferencias entre los demás y las propias, entendiendo que todos forman parte de un mismo conjunto denominado sociedad. En este sentido, una persona (ser humano) está llamada a ser virtuosa (buena y justa), y tal estado de plenitud y contemplación se logra a través del esfuerzo personal y de la práctica reflexiva en la cotidianeidad, que a esta altura ya se configura como trascendencia (fin). Ahora bien, la realización de estos fines para la persona perfila la educación como campo de cultivo para el conocer y el entender desde el descubrimiento.

En consecuencia, para Tomás de Aquino, el conocimiento se centra en el realismo gnoseológico, es decir, presupone la existencia de un mundo real que forma parte 
(no depende) del conocimiento. En este sentido, conocer es una facultad que poseemos las personas (naturaleza racional) y entender es un proceso dado por la acción humana mediante los sentidos externos (oído, vista, gusto, tacto, olfato) e internos (sentido común, imaginación, estimativa y memoria); por lo tanto, ambos privilegian la experiencia (el saber individual) y son propositivos, es decir, implican una formación y una transformación (Basso, 2012). Ahora bien, para Tomás de Aquino, el conocer no siempre implica acción sobre lo físico, pues en muchos casos forma parte del intelecto; por ello es necesario también potenciar el intelecto, lo cual es posible desde la educación.

Hablar sobre conocer y descubrir es, entonces, referirnos a ser y saber, facultad y proceso, materia y forma. Conocer conlleva la reflexión y el descubrimiento desde el juicio y desde la experiencia, por ello es algo que se crea dentro de la persona y que se puede enseñar y desarrollar a partir de un núcleo autónomo previo, partiendo de la premisa de que todas las personas conciben en sí mismas nociones generales y comunes. Entonces, para Santo Tomás, tanto el conocimiento como el aprendizaje son procesos vitales y activos que permiten descubrir la naturaleza con realismo.

Si entendemos el entender, podremos decir si es o no ajustado a lo real, y cómo. No se trata, pues, de un realismo dogmático y acrítico, pues hay toda una crítica del conocimiento para demostrar esa tesis realista por la que se ha optado. Se pone como tesis y se arguye a favor de ella, y la argumentación recoge el dinamismo propio del conocer. Pero tampoco es un criticismo trascendental, pues Tomás se da cuenta de que si parte del lado del sujeto nunca podrá acceder al del objeto; si se toma como punto de partida lo epistemológico jamás se puede inferir lo ontológico. (Bouchet, 1989, p. 11)

Considerando esta perspectiva, podemos asumir el conocimiento desde dos niveles cognoscitivos: el empírico y el intelectual, los cuales se configuran como un camino inductivo que va del conocimiento de lo singular a lo universal, buscando el principio general que dé cuenta del hecho particular. En este orden de ideas, el conocer viene a ser un proceso de abstracción por el cual se diferencia lo inteligible de lo sensible de las cosas, es decir, lo intelectual y lo sensible. Para esto último se gesta un conocimiento desde los sentidos, a fin de descubrir la realidad tal y como se presenta, mientras que para lo primero el conocimiento es abstracto y universal, es la realidad asumida y comprendida.

De esta manera, el conocer y el descubrir se asocian con el contemplar y el actuar, como complementarios, puesto que la vida contemplativa y la vida activa se 
reconfiguran en una vida mixta, en la cual lo que se contempla (descubre) genera una acción (conocimiento). Lo anterior se puede interpretar, desde el campo de la educación, como aprendizaje y enseñanza, ya que la educación, como la vida misma, es contemplativa e incesante a la vez. De igual manera, descubrir y conocer determinan a su vez el quehacer del maestro en la medida en que este contempla la realidad $y$, posteriormente, actúa con base en la verdad para poder comunicarla. Este último acto pedagógico supera el transmisionismo, no significa pasar la verdad, sino comunicar y dialogar dicha verdad para enriquecerla y perfeccionarla y, de esta manera, permitir que el estudiante a su vez la contemple (conozca) y posteriormente la actúe (aprenda).

Con todo esto, podemos ahora cuestionar: ¿qué se descubre y qué se conoce? Santo Tomás de Aquino al igual que Aristóteles encuentran la respuesta en la naturaleza de la realidad. Es decir, el descubrimiento y la invención constituyen un proceso inductivo que permite que se descubran las cosas como son naturalmente; comprender desde la inventio es partir del entendimiento para, después, hacer reflexiones y comparar sistemáticamente la naturaleza y la realidad. Por último, se sacan las conclusiones, y a partir de estas se forman imágenes pertinentes de lo que se descubre y lo que se conoce.

Es decir, descubrir y conocer significan apropiarse de la realidad, entender y conocer desde los aspectos sensibles hasta los procesos inteligibles, desde los primeros principios hasta las conclusiones (Martínez, 2003). Ahora bien, este proceso inductivo suprime de tajo la pasividad del conocimiento. Según como lo concebía Tomás de Aquino, se parte del conocimiento preexistente, es decir, de los saberes previos de la persona que se nutren, refutan o consolidan desde la imitación de la realidad (naturaleza), pasando de un estado de potencia activa, entendido como un proceso de descubrimiento natural, a un estado de ciencia, conocido como proceso de aprehendimiento de la naturaleza. Precisamente, es en este último punto donde el santo enfatiza, pues entiende que la educación es un vehículo mediante el cual se logra el tránsito entre descubrir y conocer (Martínez, 2003).

Si, según Santo Tomás, se educa a la persona y sus facultades incorpóreas y corpóreas (figura 1), ¿por qué se afirma que se educa a la persona desde su naturaleza racional (entendimiento y voluntad) para categorías de la vida intelectual? Educar el entendimiento presupone educar en y para un fin (un bien conveniente); por tanto, más que educar se trata de comprender que el entendimiento surge de la experiencia mediada por los sentidos (internos y externos). 


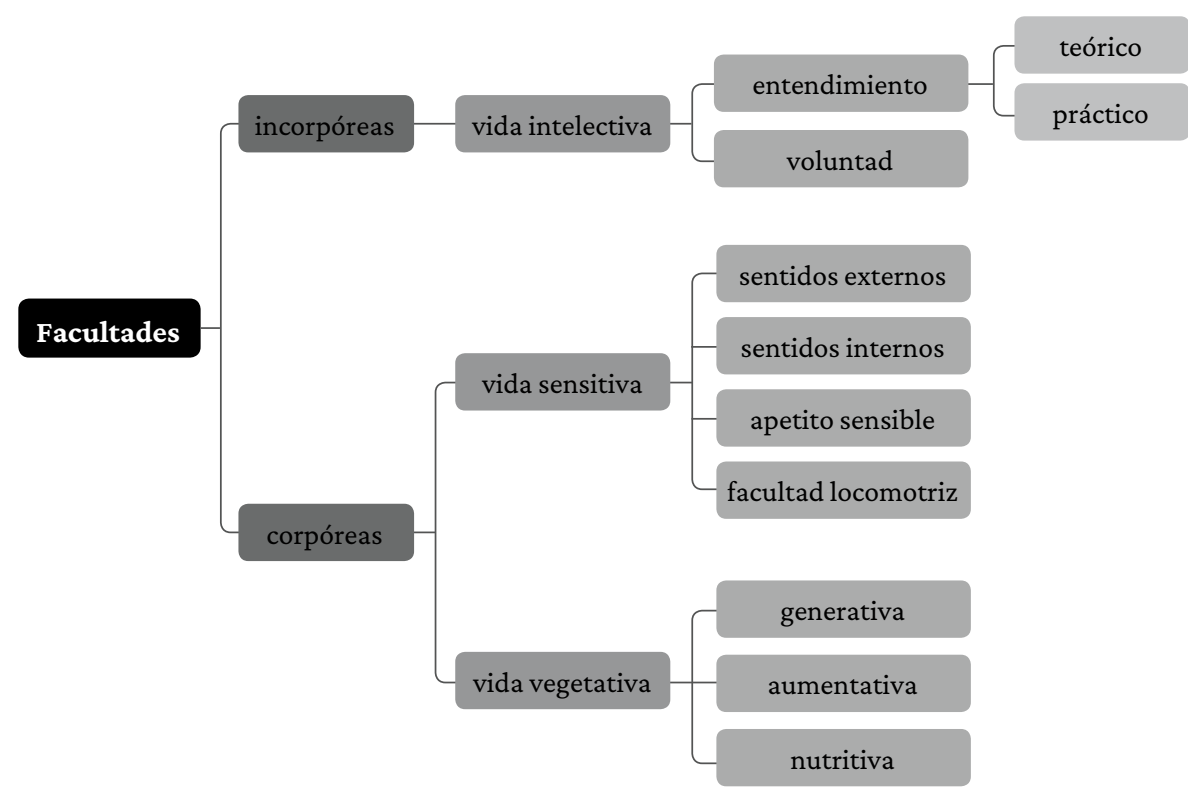

Figura 1. Facultades humanas según Tomás de Aquino.

Fuente: elaboración propia.

Educar la voluntad es la respuesta concreta al cuestionamiento sobre qué educar (figura 2). Por esta razón, al entendimiento se le atribuye el conocer tanto de la realidad interior como de la exterior, que es a su vez introspección y descubrimiento y que tiene, como fin último, la búsqueda de la verdad. Así, el conocimiento permite a la persona ejercer conciencia propia sobre lo que es y lo que sabe. Esta toma de conciencia involucra reconocer sus capacidades y sus responsabilidades respecto a la realidad, paso que es cumplido mediante la educación. En esta misma línea, a la voluntad se le atribuye el amor, y por tal razón su objetivo es perseguir el bien y la verdad, proceso de búsqueda cuyo resultado final es la emancipación. La voluntad se puede entender así como el impulso propio (lo que mueve) del espíritu; citando a Santo Tomás (1988): "La voluntad presupone la inteligencia”.

Entonces, la voluntad por sí sola no tiende a las cosas buenas, pues solo propende hacia aquello que la inteligencia le propone como bueno o conveniente. Aquí es claro cómo la voluntad depende del entendimiento y, por consiguiente, se deben educar ambas. Al ser la voluntad aquello que mueve, la educación debe priorizarla, pues esta permite la acción en el bien y la verdad; en términos de Tomás de Aquino, se educa en la virtud moral. 


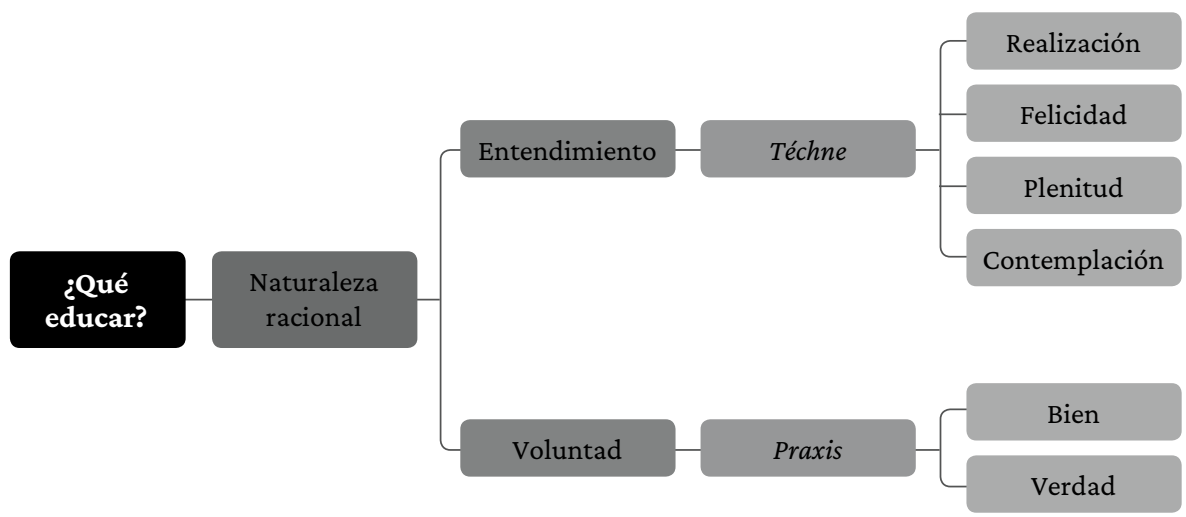

Figura 2. ¿Qué educar, según Tomás de Aquino?

Fuente: elaboración propia.

De esta forma, la voluntad es permeada por el entendimiento, pero solo la voluntad puede mover las otras potencias de la naturaleza racional. En este sentido, el acto de entender es causado por la voluntad, es decir, conocer es querer y se quiere lo que se conoce; lo que se quiere conocer está en el intelecto, es decir, es lo bueno y lo justo, y es allí hacia donde se debe encaminar la voluntad a través de la educación

El conocimiento se realiza en cuanto que las cosas conocidas están en el que las conoce. [...] En cambio, el acto de la facultad apetitiva consiste en que el afecto se inclina hacia una cosa exterior [...]. Es propio de una y otra potencia que algo (en este caso, el alma humana) tenga en sí lo que existe fuera de ello (en el conocer), y que ello mismo tienda hacia la realidad exterior (en el querer y amar). (Tomás de Aquino, 1988, ST H I, qu.59, ar.3, ad.2)

Por eso, para Tomás de Aquino, educación es e-duce, es decir, sacar de dentro, conducción del ser hacia el mismo ser que se complementa con la inspectio, con la mirada atenta a lo que se educa y al que se educa. La educación es la potencia que permite que el descubrir (contemplación) logre pasar al conocimiento (acción). Para Aristóteles, pasar de la téchne a la praxis consiste en que la persona comprenda la ciencia, la sabiduría y la virtud en sí mismas, y posteriormente las haga inteligibles, las haga suyas a través de la comunicación, del actuar de la vida virtuosa, buena y justa (Reyes, 2016). 
Por ello, el intelecto y en especial la voluntad son los objetos de la educación. Una formación en la voluntad le permite a la persona no solo actuar sino saber actuar, la encamina hacia el bien, hacia la perfección de su ser, su saber y su querer. De ahí que educar la voluntad sea educar para la trascendencia. Sin embargo, es importante señalar que no se debe descuidar la educación del intelecto por causa de la educación de la voluntad, dado que la persona es persona en la medida que edifique su integralidad y su unicidad.

La educación integral incluye, entonces, la educación del ser en su hacer (yo), en su obrar (alteridad), en su ejercicio de comprender (cognición) y en el acto de comunicar (trascendencia). Educar es perfección, es la búsqueda del camino de la virtud, del obrar bien, de la libertad y voluntad. Ahora bien, este estado de virtud, como se ha explicado anteriormente, no es un proceso desconectado de la realidad, del otro y de lo otro, sino que, siguiendo a Reyes (2016):

El obrar humano es virtuoso cuando construye relaciones justas en su sociedad.

Tales relaciones justas, en el bienestar de todos, hacen posible la aspiración humana a la felicidad. Así, podemos indicar que la educación es también una actividad que procura la plenitud humana en la vivencia personal y comunitaria de la felicidad. (p. 61)

Y es justo aquí donde el pensamiento de Tomás de Aquino afirma que la educación debe propender al conocimiento activo y no solamente al pensamiento, dado que la realidad está ahí para ser conocida no de manera exclusiva desde lo sensible, sino también desde lo racional; de esta manera, el objeto deviene trascendente en la medida en que lo descubro, y no solo porque lo pienso. El pensar busca que el objeto sea previamente analizado (pensado) y después sea confrontado con la experiencia para sintetizar la idea previa. Lo anterior fracciona el entendimiento entre lo que se conoce (se piensa) y lo que no se conoce, desvistiendo así la realidad de descubrimiento y asombro, despojando al conocer del ser, ya que solo es lo que se piensa, el objeto que no se piensa no existe.

La diferencia entre pensar y conocer se configura así como el borde, la frontera que separa el realismo del idealismo crítico. El pensar no exige objeto determinado por la sensibilidad, mientras que el conocer sí. Por tal razón, en el pensamiento escolástico de Aquino se educa la concepción unitaria de inteligencia (entendimiento y voluntad), cuya finalidad es la realidad y cuyo objeto es lo inteligible que está inscrito en las cosas físicas, no desde una dualidad, sino a través de un camino de validez, de 
búsqueda de la verdad a partir de la realidad presentada, en un ejercicio educativo libre que busca entender la trascendencia del objeto y de sí mismo.

Aquello que nos mueve a descubrir la verdad es la voluntad, pero esta acción no es ciega ni desmedida, sino que es un camino para abordar la realidad, un camino para hacerse libre. Quien conoce, logra comprender la realidad; quien conoce, puede; y quien puede, logra ser libre. Por lo tanto, el que se educa es libre, y el que es libre, es feliz.

\section{Descubrir la verdad como propósito de la educación}

Lo dicho previamente establece una clara conexión entre el conocer, el ser y la verdad. La intención del ser humano no está, entonces, en el saber sino en la verdad, ya que esta logra perfeccionar el conocer: la persona se hace virtuosa en la búsqueda de la verdad con amor y con disciplina. El camino de descubrir la verdad se sintetiza en las concepciones sobre educabilidad, enseñabilidad y estudio que Tomás de Aquino exhibe en su ideario educativo, pero, sobre todo, en asumir que cuando se habla de educar se habla de un acto para la vida que se desarrolla durante el proceso de formación en valores y en virtudes, con capacidades enfocadas en el ser y en el convivir (Rodríguez, 2005).

En otras palabras, educar es descubrir la verdad, es alcanzar la plenitud y la virtud en el intelecto, en lo social, lo emocional, lo cultural y lo moral; educar es formar integralmente. Así, las virtudes son cualidades varias y, siguiendo a Martínez (2003), las podemos clasificar en:

- Virtudes morales, que se orientan a descubrir lo bueno.

- Virtudes intelectuales, que buscan la verdad.

- Virtudes intelectuales prácticas, que a través de la estética y la responsabilidad proyectan actos prudenciales.

Descubrir la verdad implica, entonces, educar en lo bueno, lo verdadero y lo justo. Para Tomás de Aquino, la condición de educabilidad de la persona radica en la posibilidad de ser buena y virtuosa, con un carácter multidimensional que permanentemente se relaciona con el otro y con lo otro; por ello, la persona está constantemente en una condición de ser inacabada, buscando construirse y deconstruirse 
desde sus constantes significaciones respecto a lo individual y lo colectivo. De este modo, la educabilidad consiste en revestir de fundamento las dimensiones humanas (vegetativa-orgánica, animal-sensitiva y racional-intelectiva), educando así el cuerpo, la voluntad y el raciocinio.

En este mismo sentido, la enseñabilidad implica superar los postulados empíricos del aprendizaje memorístico y repetitivo para centrarse en la educación virtuosa como principio activo de la enseñanza, el cual garantiza las categorías ontológica, nutricional e instructiva del proceso de aprendizaje. La educación virtuosa logra contextuar de este modo la búsqueda de la verdad, permitiendo de esta manera saber cómo hacer las cosas aprendidas (razonamiento técnico 'téchne') y, sobre todo, logrando que lo que se sabe se incorpore de manera reflexiva (práctica 'praxis'). Así mismo, la educación virtuosa permite que las acciones materiales, es decir, la creación y la materialización de las ideas, se planteen de forma tal que dicha acción esté acorde con los principios y fines de bien, verdad y justicia (actuar 'poiesis') y así lograr que el saber en su conjunto esté encaminado hacia un horizonte de reflexión (prudencia 'phrónesis').

Este proceso de descubrir la verdad a través de la educación requiere de la participación activa del estudiante, con estudio o disciplina, según Santo Tomás. El estudio permite que el estudiante descubra su propia verdad (conocimiento), la constate con la realidad y con los otros (alteridad) y lo otro (comprensión y conocimiento), que ponga en práctica de manera virtuosa la verdad, la justicia, el bien y el amor (cognición) y, sobre todo, que desde esa comunicación con su ser y su conocer cambie su yo y su entorno, es decir, logre transformaciones.

El acto educativo como búsqueda de la verdad permite así entrever el aprendizaje y la enseñanza como condición de vida y realización personal que supone la afirmación de la razón con autosuficiencia, para el logro de una vida contemplativa y proactiva encaminada a la realidad y la justicia como bien común. En ese sentido, la exploración de la verdad es la razón última del acto educativo para Tomás de Aquino. Su objetivo se alcanza por tanto gracias a una pedagogía realista (realismo pedagógico), que tenga preferencia por la persona y por su desarrollo humano e integral; que promueva el amor por el otro (alteridad) y por lo otro (comprensión y conocimiento); y que permita la libertad y madurez (emancipación), al entender que la persona es la principal responsable de su formación (Rodríguez, 2005). 
El fundamento último de esta pedagogía tomista no es otro que el concepto de persona que tenía el Aquinate, pues de la perfección racional de una persona fluye una acción educativa dirigida a otra persona, amada por lo que es y puede llegar a ser. La educación se nos revela de este modo como una actividad inmersa en la vida personal. (Martínez, 2003, p. 20)

La formación de todas las facultades humanas, entiéndase las incorpóreas y las corpóreas, son la razón del descubrimiento de la verdad. Las facultades incorpóreas comprenden el entendimiento y la voluntad, mientras que la vida sensitiva y la vida vegetativa pertenecen a las corpóreas. Todas estas, en su bien último, determinan la plenitud de la persona en la acción prudencial.

Educar en la prudencia es lograr en el hombre el status virtutis del que habla Santo Tomás, en la medida en que únicamente a través del desarrollo y perfeccionamiento de ella pueda lograrse que las semillas de la virtud morales, connaturales a nuestro ser, germinen y den fruto cada vez más granado y abundante. (Millán, 1989, p. 86)

Finalmente, para Santo Tomás de Aquino, la búsqueda de la verdad es realizable mediante la educación. La educación permite formular juicios y aprehensiones que sean verdaderos, y posibilita que dicho estado se consiga autónomamente mediante un proceso inductivo de dos vías: la primera, que el estudiante llegue a las conclusiones desde sus conocimientos previos (aprendizaje), y la segunda, fortaleciendo su entendimiento a través de conexiones entre los principios y la conclusión (enseñanza). La educación en ese sentido es más que instrucción; es búsqueda de la virtud, es adquisición de acciones, motivos y modos de sentir en la verdad, es vivir y evidenciar la verdad, la justicia, lo bondadoso; no basta con comprender estos conceptos, sino que es necesario vivirlos.

\section{Propósito de la educación para Santo Tomás}

El propósito de la educación en la obra Tomás de Aquino viene a ser la formación integral de la persona. Esto se apoya en el hecho de que el proceso educativo debe ser verdadero, virtuoso, prudente, comunicativo y transformador, lo cual permite el desarrollo armónico y coherente del ser humano desde una perspectiva ética, espiritual, cognitiva, afectiva, comunicativa, estética, corporal, política y ecológica. Sin 
embargo, esta formación no debería repartirse en compartimientos separados (asignaturas, módulos, materias, cátedras, etc.), sino estar permanentemente integrada en la práctica pedagógica de los maestros.

Desde el realismo pedagógico, dicha práctica se centra, en primera medida, en la sensibilidad y el desarrollo socioafectivo, es decir, en principio el contenido de la asignatura no es lo trascedente, sino que esta permita que el estudiante se haga más digno, más humano. Esta pedagogía de lo sensible y para lo sensible implica una educación verdaderamente humana, más allá del pragmatismo y del utilitarismo y centrada en la alteridad, la caridad y la compasión. A menudo se prioriza el desarrollo de la inteligencia, es decir, de la capacidad de resolver problemas, crear productos para un contexto específico, dar respuestas coherentes y acertadas, es un tipo de educación que prioriza la capacidad de respuesta más que la cantidad de información que posee un estudiante. Sin embargo, no basta con la inteligencia, sino que se debe dar cuenta del desarrollo de la razón, es decir, de la capacidad de reflexionar sobre la propia inteligencia y de tomar decisiones prudentes. Y en esta etapa la persona prudente no es aquella que deja de hacer cosas, sino la que las hace con un horizonte de eticidad y moral, siempre con el fin de perseguir la verdad y la justicia.

Por último, está el desarrollo de la libertad, entendida como la felicidad, la plenitud. Este estado se encuentra en la acción prudencial como acción y transformación, es decir, como verdadera transformación del yo y de la sociedad a través de lo aprendido y aprehendido en el aula de clase; este es el verdadero reto. La educación para la libertad no es una educación para el anarquismo sino para la sociedad, para la cooperación y para la comunidad; este es su verdadero propósito desde la perspectiva del realismo pedagógico. ¿Cómo lograrlo entonces?, ¿cómo hacerlo más real y menos utópico? Ante este cuestionamiento, es necesario señalar los principios de la educación que Santo Tomás identifica:

1. Principio de virtud. Orientado hacia el "estado perfecto del hombre en cuanto hombre, como fin de la educación” (Martínez, 2004, p. 85). En efecto, "por la virtud se llega a ser un hombre bueno, justo, prudente" (p. 82).

2. Principio del amor. El que une la inteligencia y el amor para poder educar en la verdad, porque solo ella nos hace libres. El amor es aquí una emoción que da objetividad al intelecto. 
3. Principio de libertad y madurez. Implica una actitud de crecimiento y mejora intrapersonal, camino que requiere ser recorrido con el acompañamiento de un maestro.

4. Principio de la primacía de la persona. Consiste en enfocar el aprendizaje y potenciar la energía y las capacidades del individuo, con el fin de que este encuentre su plenitud.

5. Principio de verdad. "El maestro conduce y guía al discípulo por el camino que lleva a la verdad” (Millán, 1989, p. 135).

6. Principio de la palabra humana. "No solo se educa la palabra interna del educando, sino que se educa desde la palabra externa del maestro [...] no es necesario ni siquiera recurrir a la voz, pues una mirada o el propio ejemplo, si surgen del corazón, consiguen mucho más que largos discursos” (Martínez, 2003, p. 31).

7. Principio de prudencia. Entendido como la praxis de la decisión real y concreta, en el que el criterio lo presupone la persona prudente; quien logra valorar cada alternativa de solución desde sus propios principios, los cuales responden a los reclamos de los bienes materiales y a las obligaciones de los bienes espirituales, buscando que con su accionar se logre contribuir al perfeccionamiento propio y común (Restrepo, 2017).

\section{Realismo pedagógico}

Es difícil poder sintetizar el ideario educativo de Santo Tomás de Aquino en una sola tendencia o metodología, con el riesgo que corren los ismos como determinantes de teorías personales. En todo caso, para nuestro autor la educación sobrepasa este tipo de reduccionismo y se centra en la formación integral. Según el santo, la persona no es un ser intemporal, es un ser anclado en la vida y en las cosas de la vida; es un realismo, un ser educable. Por tal razón, hablar de realismo educativo, o si se quiere realismo pedagógico, en Santo Tomás, es hablar de la experiencia humana; no es hablar de una corriente y mucho menos de una teoría educativa, no responde a cómo hacer educación sino para qué educar. 
En ese sentido, el realismo pedagógico tomista da primacía a la formación del carácter, de los hábitos y de la personalidad, debido a que los fines de la educación no pueden ser otros que los fines de la existencia humana, por lo cual esta posee un sentido eminentemente trascendente: tanto para la educación como para la persona, el fin es la virtud, la felicidad, el bien y la justicia. En este orden de ideas, el realismo pedagógico tomista es personalista, parte del concepto y respeto de la persona; además es virtuoso, ya que busca que el estudiante no solo obre bien, sino que su accionar se alinee con la virtud en un estado de prudencia.

Todo lo anterior refiere a que el realismo pedagógico tomista es una invitación a la educación para la prudencia, pues esta permite que la voluntad pueda acceder rectamente a los medios y mediaciones que le permitan conocer intelectualmente $y$, por ende, obrar de manera prudencial. Tal estado de prudencia es considerado por Santo Tomás como el estado perfecto de la persona, ya que le permite autogobernarse en su libre albedrío, desde un actuar justo y bueno. Y es en este punto donde esta aproximación aparece como metodología pedagógica por cuanto permite que el estudiante viva la realidad y la verdad mediante la obediencia, la autodisciplina, el autoconocimiento y la deliberación.

En términos pedagógicos, esta es una metodología que vela, en primera instancia, por el conocimiento y dominio de las facultades intrapersonales, y en segunda, por la solución de problemas y la comunicación asertiva. Es decir, es una educación holística o integral. De esta forma, cuando el estudiante logra conocerse a sí mismo (lo intrapersonal), aprende el valor de la alteridad y del reconocimiento del otro y de lo otro (lo interpersonal), puede abordar la realidad tal y como se le presenta, descubriendo así la verdad, la justicia y la bondad (solución de problemas) y, por último, se comunica, mueve, dialoga y enseña asertivamente (comunicación asertiva) desde una perspectiva del actuar prudencial.

A partir de esta aproximación pedagógica se logra abordar el entendimiento de la práctica educativa en relación con la ética, la lógica y las artes (para Aristóteles, téchne, praxis y poiesis), concibiendo la educación como un espacio donde se vivencia la libertad, la moral, el cuerpo y el conocimiento, no como concepto abstracto, sino como educación real. La práctica pedagógica busca, entonces, conocer el ser y no pensar el deber ser: supone praxis, quehacer, superando la concepción de trabajo mecánico propio de la téchne; además de que se introduce en un registro más amplio de phrónesis, esto es, acción que implica interactividad, experiencia, compromiso y valores en la acción política dentro de la polis (Pineda y Orozco, 2016a), ahora regidos por el interés de libertad, verdad y justicia. 
Se trata de ejercer una verdadera praxis capaz de otorgar los medios necesarios para que los individuos se eleven a la categoría de sujetos históricos. Esto significa que el maestro no puede continuar ejerciendo su praxis como un técnico o administrador de currículo. Su labor debe estar encaminada a la emancipación, lo que exige la implementación de prácticas pedagógicas capaces de distinguir de manera inteligible las intencionalidades, las estrategias, los medios, los contextos y, especialmente, los aspectos constitutivos de los sujetos de la formación. (Pineda y Orozco, 2016a, p. 13)

En el realismo pedagógico tomista, conocimiento y acción se entienden como unidad, por lo que el conocimiento se hace desde la autoformación, desde la educación de la voluntad y en las virtudes, lo que en consecuencia genera "una apuesta permanente por la lectura de la realidad a través de un paradigma cualitativo" (Pineda y Orozco, 2016b, p. 144). Esto implica igualmente el compromiso de comprender la naturaleza y la sociedad a través de una hermenéutica de conjunto como factor de "intervención en la construcción de proyecto de vida y de dimensiones humanas por parte de los actores educativos” (p. 144). En este sentido, el realismo pedagógico tomista "busca ofrecer esa visión de conjunto de la realidad a través de la construcción discursiva de la práctica de sus actores" (p.144), lo cual puede entenderse como una pedagogía del actuar consciente en la búsqueda de la verdad y la justicia.

\section{El realismo pedagógico tomista en el contexto de la cibercultura}

Ahora, situando la pregunta por la educación desde Santo Tomás de Aquino en el contexto de la cibercultura, sería también pertinente preguntar: ¿en qué consiste la tarea de educar en una sociedad digital hipermediatizada? Esto abre por supuesto otras preguntas: ¿para qué educar en la cibercultura?, ¿quiénes educan en la cibercultura? Ante esto, nuestro autor nos invita a recurrir al método de análisis de las cuatro causas (material, formal, eficiente y final), actualizando las premisas de Lévy (2007). Y dado que en la cibercultura es pertinente separarse del determinismo tecnológico, aquí lo importante no es preguntarse cómo educar sino para qué educar. De este modo, la atención centra la discusión en el sentido de la actividad educativa, cuestionando desde el realismo pedagógico tomista el tipo de educación que se necesita en una era caracterizada por altos flujos de información, interactividad y despersonalización. 
Precisamente, para Lévy (2007), las reflexiones sobre el papel de la educación en el contexto de la cibercultura deben centrarse en los cambios que experimenta la relación entre conocimiento y persona. El pensamiento tomista nos indica a su vez que la educación no puede reducirse a la mera instrucción, no resulta pertinente enfocarla solo al intelecto. En este orden de ideas, entender la educación contemporánea desde el prisma de los conocimientos, la competitividad, la productividad y el rendimiento económico, despoja al acto educativo de la responsabilidad de coadyuvar con el desarrollo de proyectos de vida en los estudiantes. Por tal razón, siguiendo a Lévy y Tomás de Aquino, la educación en la cibercultura debe empezar por la voluntad, para saber y conocer, para afrontar lo complejo de la realidad y para sortear las incertidumbres.

Por ello, la preocupación de Lévy (2007) respecto a la velocidad con que el saber y el saber hacer se renuevan en la cibercultura, ya que los conocimientos adquiridos se hacen obsoletos cada vez más rápidamente. Ante esto, se debe tener muy presente que el objetivo de la educación debe ser, ante todo, la conducción y la promoción de la persona a un estado de perfecta plenitud, que, según Tomás de Aquino, es el de la virtud. En otras palabras, la educación en la cibercultura no debe dar mayor importancia a la acumulación de conocimientos sino a las capacidades agentivas que permiten a las personas asumir la construcción responsable de su propio destino, es decir, formarse a sí mismos como individuos. Para esto se debe comprender que un estado de virtud no es un proceso inmediato, sino más bien una empresa a lo largo de toda la vida, que requiere de un tránsito lento, de disciplina enfocada en el llegar a ser: la educación, entonces, no es substancial sino accidental, no se basta con el ser, sino que propende al ser bien.

Una persona virtuosa en el arte de tocar el violín o cualquier otro instrumento musical, en sus inicios debió esforzarse para lograr algunas notas quizá con torpeza, pero con el tiempo y un trabajo constante (disciplina) adquirió la virtud de ejecutar o componer una pieza musical con facilidad y con gusto, de tal suerte que se convirtió para ella en algo connatural y gratificante. De la misma manera, mediante un trabajo disciplinado y constante, un ser humano puede adquirir cualquier virtud tanto en el orden intelectual como en el moral. (Corchuelo, 2012, p. 82)

Por otra parte, en las reflexiones de Lévy (2007) sobre el papel de la educación en la cibercultura persiste la preocupación concerniente a las nuevas naturalezas del trabajo, pues cada vez será más importante aprender a producir y transmitir 
conocimientos que solamente poseerlos. Ante esto, Aparici y García (2018) enfatizan que en la sociedad digital la educación no se debe limitar a retransmitir sino que debe retroalimentar las praxis; el aula de clase es solo una interfaz más que cobra sentido en la medida que permite la participación e intervención del estudiante, generando así una cultura de la participación y cocreación bidireccional de aprendizajes y saberes. Estas premisas de la cibercultura reafirman las posturas de Santo Tomás de Aquino por cuanto señalan que la educación es el camino para el crecimiento del ser al permitir el reconocimiento intersubjetivo, es decir, el favorecimiento y la promoción integral de la persona. De este modo, la educación contemporánea posee también la capacidad de humanización de los actos, reconociendo en ellos las capacidades colectivas que materializan la llamada "inteligencia colectiva".

Jenkins (2008) sostiene que el acto educativo debe separarse de los intereses del mercado en la cultura de la convergencia, en la que tal mercado se entiende como la producción de saberes rentables, y más bien concentrarse en los saberes indispensables, es decir, aquellos que las personas y las colectividades requieren para dar sentido a sus proyectos de vida. Así, se revalida la tesis de que el propósito de la educación es el perfeccionamiento de la persona, pues puede desarrollar de manera armónica y equilibrada todas las potencias físicas, artísticas, intelectuales, morales y espirituales de su naturaleza humana desde un ejercicio de formación integral.

Educar es ayudar a alguien para que se desarrolle de la mejor manera posible en los diversos aspectos que tiene la naturaleza humana [...] Educar significa comunicar conocimiento, despertar habilidades y promover actitudes [...] Información y formación constituyen un binomio clave en toda educación. La primera abre la puerta, y la segunda nos instala en el proceso educativo. Son dos etapas sucesivas y complementarias. No hay educación completa si falta alguna de ellas. Recibir información es acumular una serie de datos, observaciones y manifestaciones específicas. La formación va más allá: ofrece unos criterios para regir el comportamiento, de acuerdo con una cierta orientación; pretende sacar el mejor partido posible de los conocimientos recibidos, favoreciendo la construcción de un hombre más maduro, más sólido, más humano y más espiritual, más dueño de sí mismo. (Rojas, 1999, p. 21)

En esta línea, podemos decir que el realismo pedagógico tomista propende a consolidar el papel cultural de la educación, ya que busca el mejoramiento continuo de todas las dimensiones de la vida humana; por tal razón, su papel en el contexto de la cibercultura es permitir la comprensión de una realidad holística y globalizada, 
dando relevancia al vivir juntos, al trascender y avanzar desde la solidaridad, el amor y la filiación a una colectividad. El papel de la educación en la cibercultura no se limita, entonces, a la alfabetización digital, y mucho menos al uso y manejo de herramientas digitales (lo cual es importante, pero no determinante), más bien hace énfasis en el reconocimiento de la realidad multicultural, en la cual es esencial crear condiciones de vida basadas en la solidaridad y el reconocimiento de identidades culturales.

De ahí que la mirada de la educación contemporánea se centre en ir más allá de los medios o lenguajes para ubicar su papel en la configuración cultural, para entender las nuevas formas de vida, las prácticas sociales, las emociones vinculadas a las praxis de las personas. El llamado aquí es a no invisibilizar a la persona por el objeto tecnológico, en el entendido de que la mera instrucción del intelecto es insuficiente; la educación debe preocuparse también por el cultivo de las facultades y dimensiones más esencialmente humanas.

\begin{abstract}
En Santo Tomás, podemos colegir, una educación en la virtud tendría que permitir el desenvolvimiento de todas las posibilidades de acción virtuosa. Tendría que ser fundamentalmente un proceso de actualización de las virtudes en cada ser humano, desarrollando entonces lo moral-práctico, lo intelectual-teórico y lo espiritualteológico. Tal sería la educación que convendría al alma humana, a la persona y sus posibilidades de crecimiento y perfeccionamiento. (Reyes, 2015, p. 64)
\end{abstract}

Finalmente, podemos constatar que en la cibercultura el acto educativo no modifica su fin, como es la conducción y la promoción de la justicia y la virtud, siguiendo a Santo Tomás. La educación contemporánea desde la perspectiva de Tomás de Aquino reafirma lo expresado por Lévy (2007), en cuanto a que el proceso educativo en la sociedad digital no es considerado un paso al individualismo ni hacia una colectividad que desdibuja la subjetividad y esencia de persona, sino que significa “valorizar y multiplicar al máximo el potencial del bien” (p. 26). De esta manera, se fundamenta en una constante y perenne pregunta por la alteridad y la corporeidad, siendo el aprendizaje con el otro y para el otro un freno a la amenaza de objetivación de la persona, a la vez que permite nutrir de integridad la experiencia educativa en un contexto digital. 


\section{Sobre los autores}

Fray Rodrigo García Jara, O. P. Doctorando en Educación Superior por la Universidad de Baja California, México. Magíster en Teología por la Universidad Pontifica Bolivariana. Licenciado en Filosofía del Pensamiento Político y Económico por la Universidad Santo Tomás. Vicerrector Académico de la Universidad Santo Tomás, Sede Villavicencio. Sus áreas de interés versan sobre la educación, el tomismo, el humanismo cristiano tomista y la sociedad digital.

Édgar Pineda. Doctor en Humanidades y Sociedad Digital por la Universidad de La Rioja, España; doctor en Educación por la Universidad de Baja California, México; magíster en Neuropsicología y Educación por la Universidad Internacional de La Rioja (UNIR); magíster en Educación por el Instituto Tecnológico de Monterrey (TEC), México; y licenciado en Filosofía del Pensamiento Político y Económico por la Universidad Santo Tomás, Colombia. Actualmente es docente de la Unidad de $\mathrm{Hu}$ manidades y Formación Integral de la Universidad Santo Tomás, Sede Villavicencio. Áreas de interés: humanidades, educación y estudios en cibercultura.

\section{Referencias}

Aparici, R. y García, D. (2018). Comunicary educar en el mundo que viene. Gedisa.

Aquino, T. d. (1988). Suma de teología, II-II. BAC

Basso, D. (2012). Las potencias y facultades humanas según la antropología tomasiana. Sapientia, 68, 231-232. http://bibliotecadigital.uca.edu.ar/repositorio/revistas/potencias-facultades-humanas-basso.pdf

Corchuelo, F. (2012). Reflexiones sobre la educación integral a partir del pensamiento de Santo Tomás de Aquino. Espiral, Revista de Docencia e Investigación, 2(1), 79-92. https://doi. org/10.15332/erdi.v2i1.122

Jenkins, H. (2008). Convergence Culture. La cultura de la convergencia de los medios de comunicación. Paidós.

Lévy, P. (2007). Cibercultura. La cultura de la sociedad digital. Anthropos. Universidad Autónoma Metropolitana.

Martínez, E. (2003). Persona y educación en Santo Tomás de Aquino. Fundación Universitaria Española.

Millán, A. (1989). La formación de la personalidad humana. Rialp.

Pineda, E. y Orozco, P. (2016a). El currículo praxeológico como interés de conocimiento emancipatorio. Praxis Pedagógica, 16(18), 11-25. https://revistas.uniminuto.edu/index.php/ praxis/article/view/1365 
Pineda, E. y Orozco, P. (2016b). Currículo, interdisciplinariedad y subjetividades: otros modos de pensar y hacer educación desde la pedagogía praxeológica. REXE. Revista de Estudios y Experiencias en Educación, 15(29), 125-148. https://doi.org/10.21703/rexe.2016291251488

Restrepo, J. A. (2017). La acción humana en perspectiva prudencial, valor y alcance para la educación superior. Ediciones USTA.

Reyes, J. (2016). Educación integral en Santo Tomás de Aquino. Albertus Magnus, 7(1), 53-67. https://doi.org/10.15332/s2011-9771.2016.0001.03

Rodríguez, E. (2005). Teoría y práctica pedagógica en Tomás de Aquino. Ediciones usTA.

Rojas, E. (1999). La conquista de la voluntad. Planeta. 